\title{
Migration and Educational Situation in Socio Geographical Space of Municipality of Kamez
}

\author{
Msc. Evelina Rina \\ Ministry of Interior \\ General Directorate of Police \\ Email : evelinarina@yahoo.com
}

\section{Doi:10.5901/jesr.2014.v4n2p164}

\begin{abstract}
After the '90s, the suburban area of Kamez has been affected by a massive, rapid, abusive internal migration, not controlled by the state structures. The decision - making authorities were unprepared to host such a large mass of population, thus the consequences are numerous and chained, serious, some irreparable and with negative effects. Here we face a savage urbanization which has led not only to the misuse or physical consumption of the geographic space, but also to sharp social and economic problems. A sharp social problem, consequence of these uncontrolled demographic movements is also education. The education system has undergone a reform process, which although slowly, is particularly affecting the educational plans and programs, aiming to adapt themwith the requests of a democratic society based on a market economy. The government has also faced serious problems of the educational infrastructure inherited from the past, extended from the demographic changes, primarilyfrom the internal movements of the population and to a considerable extent, caused by the damages incurred especially during 1991 and 1997. The transition problems have increased the phenomenon of school drop out or non - enrollment considerably, significantly worsening the indicators of average duration of education and school enrollment rate. The positive indicators are particularly low for the poorest areas and strata of the population. The significant population growth is not followed by the establishment of new schools, which fortunately, recently are part of the development strategies. The lack of specialized schools and lack of specific programs have worsened the social situation of children with special needs. The public education service suffers from quality problems related to the lack of teaching aids, serious lack of teachers' requalification, outdated or rigid teaching methods, content problems etc. Education is a key factor in the sustainable and long - term development. The progress in education increases the society's emancipation degree, contributes to the improvement of competences for the active population, reduces morbidity, mortality, reduces the fertility coefficient and therefore better living conditions. Key words: structure of population by educational level, educational infrastructure, illiteracy, summer and specialized schools, school drop out etc.
\end{abstract}




\section{Migration in the Municipality of Kamez}

After years 1990 the peripheral area of Kamez was affected by a massive interior migration (population is increased about seventeen times in ratio with that of year) fast, abusively, and uncontrolled by state structures. This found the executive organs unprepared to systemize such a large population so the consequences were numerous and serious and consecutively where a part were irreparable and with negative effects. At this point we are before a severe urbanization which except others caused the physical misuse or consumption of geographical space.

The incomers profiting from lack of legislation, were established in the territory of ex farm, without applying any of the most elementary urbanization rules and out of the law. The inhabitants coming mostly from rural areas of North Region and established in an urban and peri-urban territory caused social economical conflicts, environmental ones, conflicts of properties, social tensions and insecurity for life integrity etc.

Kamza and especially Bathore is a bad example of misusing geographical area for which there must be made professional tests, debates, and multidisciplinary discussions in order not to allow such developments happen again in the future.

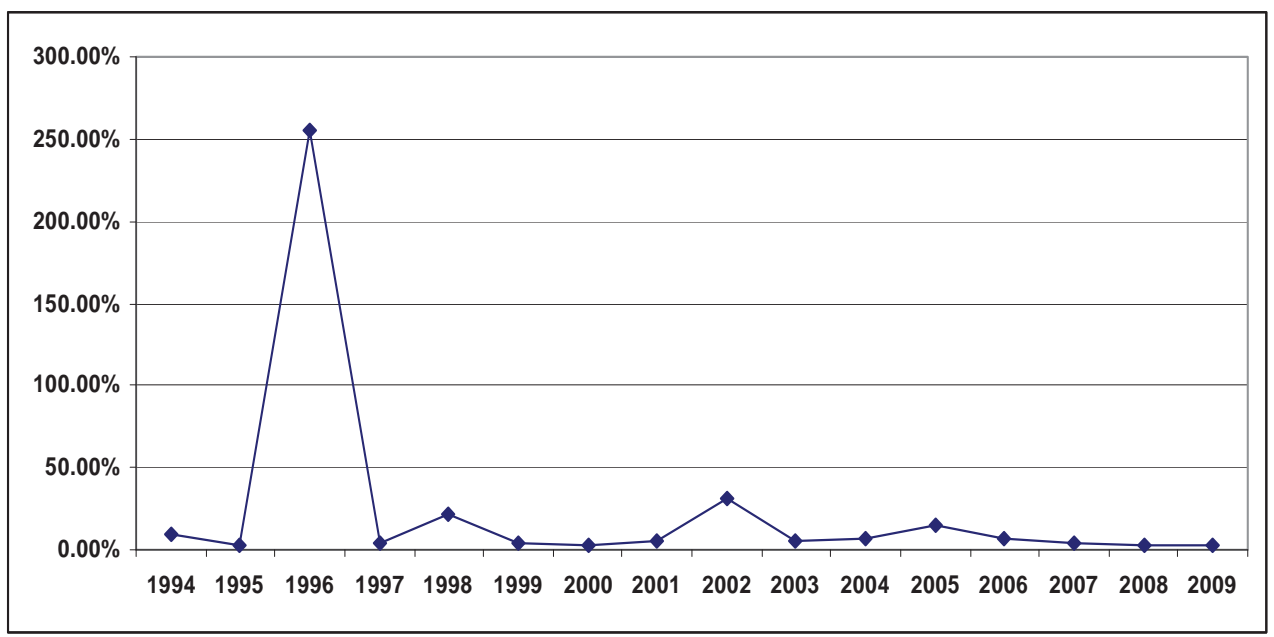

Chart 1. Rhythm of population of Municipality of Kamez increasing during the period 1994-2009 Resource: Office of Statistics, Municipality of Kamez

Comparing the rhythms of population increase in two periods 1994-2001 and 2002-2009 we notice the highest rhythm of population increase is in year 1995-1996 with $254.6 \%$. Here it is registered even the highest number of population coming and this year we have the transfer of organization from commune level to that of municipality.

From the interviews made the reasons of emigration they mention are numerous, like the economical - social factor, the educational one, health, cultural, blood in feud, for a better living etc.

\section{The educational situation in the Municipality of Kamez}

Education is a key factor of stable and long term development. The progress in education influences to the scale of emancipation of society, it contributes to the master of competences of active population, to reduce of morbidity, mortality, in lowering of fertility coefficient. 


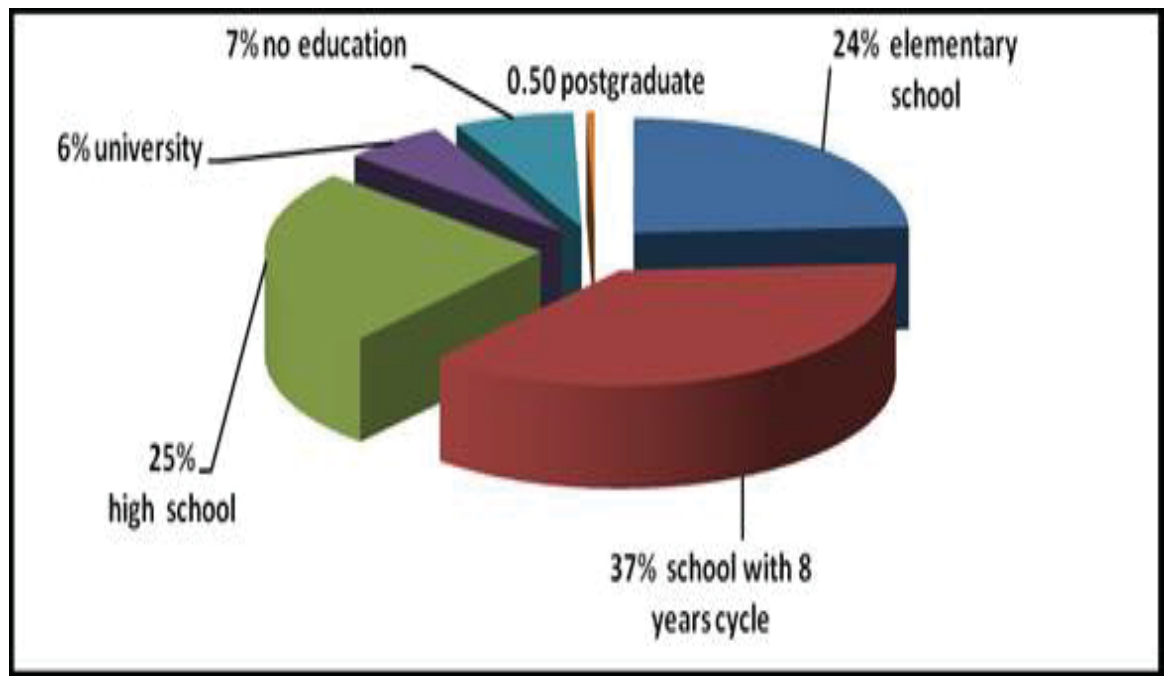

Chart 2. Part of population 25 years old and over according to educational level Municipality of Kamëz

Regarding the education of population of the Municipality of Kamez in total, the percentage of population that has made the elementary school and the compulsory one is about $61 \%$ of population. Similarly from INSTAT (year 2000) the percentage of population without education in the Municipality of Kamez was 4\%, today it is noted an increase of uneducated population with $3 \%$. From the studies made (World Bank) there is a non -linear ratio between children who live in urban areas and rural ones and more in remote mountainous areas. In these rural remote areas the percentage of children who are registered in the first grade and who complete the primary education is very low compared with the percentage of children in urban or not remote rural areas. So, in low education of incoming population have influenced not only the difficult economic, social, natural conditions but even the quality of teaching, and here there is the lack of teachers with pertinent education, lack of suitable conditions for teaching and because of small number of schools

Nationally there is not a sensitive difference between females and males at school and of their educational level.

Regarding the Municipality of Kamez it is the same situation. The difference between educated males and females is approximately $1 \%$. This proves the emancipation of society and the emancipation of females in this society.

The education system is subjected to a reformation process, though a slow one, which has affected especially the teaching plans and curricula and has aimed its adoption to requirements of a democratic society, basing on economy of market. The Government has also encountered big problems of educational infrastructure, inherited from the past, and deepened from demographic changes, above all because of interior movements of population and considerably caused from damages submitted mainly during years 1991 and 1997. The problems which have accompanied the transition period have caused the serious increase of the phenomena of leaving school or not even registering at school, aggravating sensitively the indexes of average extension of school and of rate of registration in school. The indexes mentioned above are especially low for the areas and poorest classes of population.

According to a study of the World Bank, the reduction of level of registration at school is reflected in the index of average extension of school. This index in 1989 was 11,6 years but up to 1998 it fell to 9,5 years which means that a loss on average of two years of education for a decade. Meanwhile, in the number of students who follow the higher studies there is an increase, from 10 to 17 percent comparing with year 1990.

The number of gypsy pupils who frequent the school is 179. The greatest number is reached at 9 years school in Valias (65 pupils) followed by that in Zall-Mner with 43 gypsy pupils.

According to the Educational Office of the Municipality of Kamez from 2007 and in continue a series of policies are taken in assistance of analphabet people and of gypsy children in order to integrate them. Some of them are as following:

- Removal of fines to parents who have unregistered children at school age and free registration of them.

- $\quad$ Opening of summer courses

- Providing teachers who know gypsy language

- Awareness campaign by volunteer teachers and Foreign Civil Social Organizations who have given a great 
help like CO-Plan, Global Care, AIBI (Bathore), Women in Global Action, Caritas Albania etc.

Another big problem not only for the Municipality of Kamez but for all our country is leaving school. The reasons of leaving school are various for various levels of education. In general they reflect the changes at request and offer. In preschool education leaving is related to closure of public institutions. The number of kindergardens in 2000 was reduced with 42 percent comparing to that of year 1990 (66 percent in urban area and 34 percent in rural one) nationally (according to Ministry of Education). The high levels of unemployment for females also influence to reduction of request.

All the children who abandon the low cycle of school and do not come back any more remain analphabet of course. After contacting teachers of 9-years schools in the Municipality of Kamez we learned that the biggest number of pupils who abandon school is composed of children who have problems in family especially of economic sort. These children are those who suffer the big poverty as a consequence of not having one of parents and the worst any of them. A part of children abandon school because parents themselves consider their kids as work force to help them. As a result, the interventions with employment policies will bring an improvement to the educational situation and vice versa.

The percentage of pupils who abandon high school is low from year to year and this is possibly related to the fact that feeling adults make them conscious for the school values and for the fact that the higher educational level means a chance to get a better job and as a result a better life.

Except the big problem of abandoning school we have the other problem of leaving by pupils and this is in a high percentage especially for the schools of the Municipality of Kamez. Pupils leave from schools of the Municipality of Kamez as a result of searching for a higher educational standard transferring to public or private schools of the Municipality or elsewhere.

Problematic is the situation concerning the average number of pupils per class (according to schools). It is noted a high number of pupils in the 9-years education and especially in high schools. For the 9-years education the highest number of pupils for class is at School Center of Kamez and Bulçesh and this causes problems to the teaching process and as a result to catching of lessons by pupils. The sitaution is still problematic for two high schools in Kamez and Bathore where the average number of pupils per class is still high. This large number of pupils per class in high schools brings numerous problems not only in teaching aspect but even other problems of age because they are in a very delicate age and they need a special attention which is impossible to have with classes with such a number of pupils.

The sensitive growth of population has not been accompanied by the proper number of building new schools which fortunately is made part of development strategies. The average number of pupils per class, at 9 years schools is 30-32 pupils while for high schools this number goes to 37-45 pupils per class. The vocational high school presents a less problematic situation with average number of pupils per class (24 pupils).

Regarding the number of teachers during last years it is noted an increase of number of teachers in total and in areas.

The lack of specialized schools and lack of special curricula have aggravated the social situation of children with special needs. The public educational service suffers from quality problems, which are related to absences of teaching instruments, serious absence in requalification of teachers, of old methods or limited teaching methods, problems of content of books etc. The quality of low cycle of education in rural areas, in remote areas or peri-urban ones is low. (referring to World Bank).

But we have to underline that during the last years in the Municipality of Kamez it is reached a high progress regarding the improvement of social life of community and especially in education, comparing it with previous years. Though in 2006 there were 8 objects (schools, kindergartens) in total, in 2013 they reached in 23 objects including new schools and kindergartens together with the restored ones. During this time 9 schools of 9 years cycle and of high school education have been built, restored, and completed with contemporaneous standards and supplied with labs and relevant cabinets, with gyms, and with other accessory premises for a normal development of teaching process. Three new kindergartens have been built in Kamez, Zall-Mner and in Bathore. The new schools and kindergartens are all located in the neighborhoods of the city like in: Qender-Kamez, in Bathore, Laknas, Valias, Zall-Mner, Bulcesh, covering this way all the territory of the municipality. Like in the other public investments like the roads and the other objects in service of community, even the new schools and kindergartens are overall investments.

Except the construction of new educational objects, a great job is also done with reconstructions and with restoration of interior and exterior premises of existing schools and kindergartens.

Thanks to all this work Kamza aims to reduce the overload of classes, from 40-50 pupils to 32 pupils per class, according to standards provided. Moreover, the third shift, which till recently operated almost in all schools, impeding the normal learning process is already removed. As a result of these positive radical transformations in education during these years the quality of pupils in the town of Kamez is raised. This is showed even by the increasing number of 
students from Kamez who study in different universities of the country.

\section{Bibliography:}

\section{Surveys}

Municipality of Kamez, Forms of Civil Status

Municipality of Kamez, Statistics bulletin 2009-2012

Municipality of Kamez, Forms of Educational Office

World Bank, "Financing, Effectiveness and Equality in Albanian Education"

INSTAT, Statistical Bulletin for Tirana, years 2010-2012

Educational office, Municipality of Kamez 
